\title{
Uji air perasan jeruk kesturi (Citrus microcarpa Bunge.) terhadap perubahan warna resin komposit yang direndam dalam larutan kopi
}

\author{
${ }^{1}$ Annabelle A. G. C. Sibilang \\ ${ }^{2}$ Pemsi M. Wowor \\ ${ }^{3}$ Juliatri
}

\author{
${ }^{1}$ Kandidat Skripsi Program Studi Pendidikan Dokter Gigi Fakultas Kedokteran \\ ${ }^{2}$ Bagian Farmakologi dan Terapi Fakultas Kedokteran \\ ${ }^{3}$ Program Studi Pendidikan Dokter Gigi Fakultas Kedokteran \\ Universitas Sam Ratulangi Manado \\ Email: asibilang@yahoo.com
}

\begin{abstract}
Color change or discoloration of the tooth surface is an aesthetic problem that is often complained because it reduces one's confidence in terms of appearance. This problem can also occur on the surface of restorative materials inter alia composite resin. Composite resin is a tooth-colored restorative material that most people favor due to its aesthetic value. This discoloration can occur due to excessive intake of colored beverages like coffee. The treatment used for discoloration is bleaching, but these treatments have side effects. Calamondin (Citrus microcarpa Bunge.) can be an alternative bleaching agent because it contatins citric acid. This study was aimed to determine whether calamondin juice could affect the color change of composite resin soaked in coffee solution. This was a pre-experimental study with a one shot case study design. Samples were 10 composite resins with a diameter of $5 \mathrm{~mm}$ and $2 \mathrm{~mm}$ thick soaked in coffee solution for 7 days to obtain discoloration and then samples were soaked in calamondin juice for 5 days to whiten the samples. The discoloration was measured by using the CIEL*a*b* method at 60 minutes and 5 days after soaking in calamondin juice. The Friedman test showed significant changes $(p<0.05)$. Conclusion: Calamondin juice affected the color change of composite resin that had been soaked in coffee solution.
\end{abstract}

Keywords: composite resin, calamondin juice, color change

\begin{abstract}
Abstrak: Perubahan warna atau diskolorisasi pada permukaan gigi merupakan salah satu masalah estetika yang sering dikeluhkan karena mengurangi kepercayaan diri seseorang. Masalah ini juga dapat terjadi pada permukaan bahan tumpatan gigi, salah satunya adalah resin komposit. Resin komposit merupakan bahan tumpatan yang sewarna dengan gigi yang banyak digemari orang karena nilai estetiknya. Salah satu penyebab perubahan warna yaitu mengonsumsi minuman berwarna secara berlebih seperti kopi. Perawatan yang digunakan untuk masalah diskolorisasi ialah bleaching, namun perawatan ini memiliki efek samping. Jeruk kesturi (Citrus microcarpa Bunge.) dapat menjadi bahan alternatif bleaching karena karena mengandung asam sitrat. Penelitian ini bertujuan untuk mengetahui apakah air perasan jeruk kesturi berpengaruh terhadap perubahan warna resin komposit yang telah direndam dalam larutan kopi. Jenis penelitian ialah pre-eksperimental dengan one shot case study design. Penelitian ini menggunakan 10 sampel resin komposit dengan ukuran diameter $5 \mathrm{~mm}$ dan tebal $2 \mathrm{~mm}$. Sampel direndam dalam larutan kopi selama 7 hari agar terjadi diskolorisasi kemudian direndam dalam air perasan jeruk kesturi selama 5 hari dengan tujuan untuk memutihkan kembali sampel. Pengukuran perubahan warna menggunakan metode CIEL*a*b dilakukan setelah perendaman 60 menit dan 5 hari. Uji Friedman menunjukkan terdapat perubahan bermakna $(p<0,05)$. Simpulan: Air perasan jeruk kesturi berpengaruh terhadap perubahan warna resin komposit yang direndam dalam larutan kopi.
\end{abstract}

Kata kunci: resin komposit, air perasan jeruk kesturi, perubahan warna 
Perubahan warna atau diskolorisasi pada permukaan gigi merupakan salah satu masalah estetik yang sering dikeluhkan karena dapat mengurangi kepercayaan diri seseorang. Menurut survei Tin-Oo tahun 2011 yang dilakukan pada 235 pasien, sebanyak $56,2 \%$ tidak puas dengan warna gigi mereka karena diskolorisasi gigi. ${ }^{1}$ Selain pada permukaan gigi, perubahan warna juga dapat terjadi pada permukaan bahan tumpatan gigi. Di dunia kedokteran gigi, terdapat banyak jenis bahan tumpatan gigi. Salah satu bahan tumpatan gigi yang sering digunakan ialah resin komposit karena mempunyai kekuatan mekanik dan sifat estetik yang baik. Resin komposit memiliki kemampuan untuk mengabsorbsi zat warna sehingga dapat memengaruhi stabilitas warna dan terjadi perubahan warna resin komposit. Apabila warna resin komposit mengalami perubahan, maka kelebihan utama restorasi ini yaitu estetik juga mengurang. ${ }^{2}$

Salah satu faktor penyebab diskolorisasi ialah pola diet masyarakat yang sering mengonsumsi makanan dan minuman berwarna secara berlebih. ${ }^{3}$ Kopi merupakan salah satu minuman berwarna yang digemari masyarakat Indonesia. Mengonsumsi kopi secara berlebih dapat mengakibatkan pewarnaan pada resin komposit. Hasil survei Asosiasi Eksportir dan Industri Kopi Indonesia tahun 2013 menunjukkan bahwa konsumsi kopi di Indonesia pada tahun 2010 sebanyak 0,8 kg, sedangkan di tahun 2012 meningkat menjadi $0,94 \mathrm{~kg}$ dan diperkirakan di tahun 2016 konsumsi kopi perorangan dapat mencapai $1,15 \mathrm{~kg}$ pertahun. ${ }^{4}$ Survei ini menunjukkan bahwa konsumsi kopi di Indonesia semakin meningkat tiap tahunnya sehingga risiko munculnya perubahan warna gigi pada masyarakat sudah semakin besar.

Perubahan warna atau diskolorisasi dapat diatasi dengan pemutihan gigi atau bleaching. Bahan bleaching yang sering digunakan dokter gigi yaitu hidrogen peroksida 30-35\% (in-office bleaching) dan karbamid peroksida 3-15\% (home bleaching), namun bahan tersebut dapat menimbulkan efek samping antara lain dapat menyebabkan iritasi gingiva, resorpsi eksterna di bagian servikal gigi dan menimbulkan sensitivitas pada gigi. ${ }^{5,6}$ Efek negatif akibat bleaching juga dapat terjadi pada resin komposit yaitu dapat merubah kekerasan permukaan restorasi, menambah kekasaran serta keretakan dan marginal microleakage pada restorasi. Akibat adanya efek samping bahan kimia tersebut, beberapa penelitian telah dilakukan berkaitan dengan penggunaan bahan alami sebagai bahan alternatif pemutihan gigi seperti buah jeruk nipis, tomat, stroberi, dan apel. ${ }^{7-9}$

Salah satu buah yang berpotensi menjadi bahan alfternatif bleaching ialah jeruk kesturi. Jeruk ini mengandung asam sitrat yang diketahui mampu mencerahkan warna pada resin komposit karena mengandung gugus $\mathrm{OH}$ yang berpotensi menjadi oksidator yang kuat. Menurut Cheong tahun 2013, jeruk kesturi (Citrus microcarpa Bunge.) mengandung asam sitrat dan kandungannya banyak ditemukan pada jeruk yang matang. ${ }^{10}$ Jeruk kesturi merupakan buah yang penyebarannya merata di Sulawesi Utara dan selalu tersedia sepanjang tahun sehingga mudah didapatkan dan harganya murah. Jeruk ini sering digunakan sebagai bumbu makanan masakan khas Sulawesi Utara seperti dabudabu, kuah asam, dan gohu. Jeruk kesturi juga digunakan sebagai obat untuk menjaga daya tahan tubuh, obat hipertensi, kudis dan gangguan paru-paru. ${ }^{11}$

Berdasarkan uraian di atas, diketahui bahwa resin komposit dapat mengalami diskolorisasi bila seseorang mengonsumsi kopi secara berlebih, dan jeruk kesturi mengandung asam sitrat yang dapat memutihkan resin komposit. Oleh karena itu penulis tertarik untuk melihat apakah ada pengaruh air perasan jeruk kesturi terhadap perubahan warna resin komposit yang direndam dalam larutan kopi.

\section{BAHAN DAN METODE PENELITIAN}

Jenis penelitian ini ialah pra eksperimental (pre-experimental design) dengan one shot case study design. 
Penelitian ini dilaksanakan di Laboratorium Farmasi FMIPA Universitas Sam Ratulangi Manado pada bulan September tahun 2016.

Sepuluh cetakan sampel dibuat dari sedotan yang dipotong dengan ukuran tebal $2 \mathrm{~mm}$ dan diameter $5 \mathrm{~mm}$ dan diletakkan di atas glass plate dan diberi alas celluloid strip. Resin komposit dimasukkan ke cetakan sedotan menggunakan plastis instrumen sampai memenuhi cetakan, kemudian ditutup dengan celluloid strip dan dilakukan penyinaran selama 40 detik menggunakan light cured. Resin komposit yang telah mengeras dikeluarkan dari cetakan sedotan, dipoles, dan diberi label.

Larutan kopi diperoleh dari mencampur bubuk kopi robusta sebanyak 2 gr dengan air panas dengan suhu $85^{\circ} \mathrm{C}$ sebanyak $150 \mathrm{ml}$. Larutan kopi kemudian disaring menggunakan saringan untuk memisahkan larutan dan ampasnya dan dilakukan pengukuran $\mathrm{pH}$ menggunakan $\mathrm{pH}$ indikator untuk melihat tingkat keasamannya. Larutan dituang ke wadah perendaman dan 10 buah sampel direndam ke dalam larutan kopi secara bersamaan selama 7 hari kemudian waktu dan tanggal perendaman dicatat. Menurut Turkun tahun 2004, terdapat perubahan warna pada resin komposit setelah direndam kopi selama 7 hari. ${ }^{25}$ Setelah 7 hari perendaman, sampel diangkat lalu kemudian dikeringkan menggunakan tisu. Warna resin komposit diukur menggunakan Adobe Photoshop CS4 dengan metode CIEL*a*b*.

Jeruk kesturi sebanyak 100gr disiapkan kemudian dicuci dan dibelah secara melintang dan kemudian diperas dengan tangan hingga menghasilkan air. Hasil perasan jeruk kesturi disaring memisahkan air dengan biji dan ampasnya dan $\mathrm{pH}$ jeruk kesturi diukur menggunakan $\mathrm{pH}$ indikator untuk melihat tingkat keasamannya. Wadah disiapkan dan diisi dengan air perasan jeruk kesturi. Sepuluh buah sampel yang telah diberi pewarnaan kopi direndam dalam air perasan jeruk kesturi selama 60 menit dan 5 hari. Menurut Rochman tahun 2015, terdapat perubahan warna sampel yang telah direndam jeruk nipis selama 60 menit. ${ }^{8}$ Menurut Suprastiwi (2005), metode home bleaching menggunakan durasi waktu pemutihan pada gigi selama 8 jam setiap hari selama 2 minggu. ${ }^{12}$

$$
\begin{aligned}
& 8 \times 7 \text { (hari) } \times 2 \text { (minggu) }=112 \text { jam } \\
& 112 \mathrm{~m} / 24 \text { jam }=4,6=5 \text { hari }
\end{aligned}
$$

Wadah ditutup menggunakan plastik dan masukan ke dalam inkubator dengan suhu $37^{\circ} \mathrm{C}$. Tanggal dan waktu dicatat dari dimulainya perendaman kemudian amati. Setelah itu sampel yang telah direndam air perasan jeruk kesturi diangkat menggunakan pinset kemudian dikeringkan dengan tisu. Setiap sampel diukur perubahan warnanya menggunakan metode CIEL*a*b*.

\section{HASIL PENELITIAN}

Berdasarkan hasil pengukuran yang dilakukan terlihat bahwa resin komposit yang telah mengalami diskolorisasi larutan kopi selama 7 hari dapat berubah warna menjadi lebih terang setelah direndam dalam air perasan jeruk kesturi selama 60 menit dan 5 hari. Pengukuran perubahan warna dilakukan dengan menggunakan kamera DSLR dan diukur menggunakan software Adobe Photoshop dengan metode CIEL*a*b* mode Lab* color (Tabel 1).

Tabel 1. Hasil pengukuran perbedaan warna nilai resin komposit

\begin{tabular}{cccc}
\hline Sampel & $\begin{array}{c}\Delta \mathrm{E}^{*} 7 \text { hari } \\
\text { perendaman } \\
\text { kopi }\end{array}$ & $\begin{array}{c}\Delta \mathrm{E}^{*} 60 \\
\text { menit } \\
\text { perendaman } \\
\text { jeruk }\end{array}$ & $\begin{array}{c}\Delta \mathrm{E}^{*} 5 \text { hari } \\
\text { perendaman } \\
\text { jeruk }\end{array}$ \\
\hline 1 & 69,77 & 74,10 & 83,07 \\
2 & 64,14 & 69,64 & 85,17 \\
3 & 71,58 & 74,07 & 82,88 \\
4 & 74,07 & 79,53 & 85,15 \\
5 & 74,07 & 78,08 & 85,15 \\
6 & 71,57 & 74,07 & 82,32 \\
7 & 69,64 & 75,06 & 81,66 \\
8 & 71,58 & 79,53 & 81,66 \\
9 & 74,07 & 75,06 & 81,66 \\
10 & 65,32 & 73,59 & 85,15 \\
Mean & 70,58 & 75,27 & 83,39 \\
\hline
\end{tabular}

Hasil penelitian mendapatkan dari menghitung jumlah $\Delta \mathrm{E}^{*}$ dari nilai $\mathrm{L}^{*}, \mathrm{a}^{*}$, dan $b^{*}$. Tabel di atas menunjukkan rata-rata untuk perendaman pada kopi selama 7 hari adalah 70,58 dan naik saat direndam dalam air perasan jeruk kesturi selama 60 menit 
menjadi 75,27 yang berarti warna mendekati putih. Setelah direndam air perasan jeruk kesturi selama 5 hari, ratarata menjadi 83,39 yang berarti warna sudah semakin cerah. Hal ini menunjukkan adanya perubahan warna resin komposit setelah dilakukan perlakuan pada sampel dengan terjadinya peningkatan nilai $\Delta \mathrm{E}^{*}$.

Tabel 2. Hasil uji normalitas Shapiro-Wilk

\begin{tabular}{lcc}
\hline \multicolumn{1}{c}{ Perlakuan sampel } & $\mathrm{n}$ & Sig. \\
\hline $\begin{array}{l}\text { Perendaman 7 hari } \\
\text { dalam larutan kopi }\end{array}$ & 10 & 0,081 \\
$\begin{array}{l}\text { Perendaman 60 menit } \\
\text { dalam air perasan }\end{array}$ & 10 & 0,222 \\
$\begin{array}{l}\text { jeruk kesturi } \\
\text { Perendaman 5 hari } \\
\text { dalam air perasan }\end{array}$ & 10 & $0,011^{*}$ \\
jeruk kesturi & & \\
\hline distribusi data tidak normal $(\mathrm{p}<0,05)$ &
\end{tabular}

Uji statistik dilakukan untuk mengetahui signifikansi pengaruh dari perlakuan pada sampel. Sebelum dilakukan uji statistik, dilakukan uji normalitas terlebih dahulu untuk mengetahui normal atau tidaknya distribusi data. Penelitian ini menggunakan uji normalitas Shapiro-Wilk karena sampel penelitian tergolong sampel kecil $(<50)$ (Tabel 2).

Hasil uji normalitas menunjukkan sebaran data di kelompok perendaman larutan kopi 7 hari dan kelompok perendaman air perasan jeruk kesturi 60 menit normal ( $p>0,05)$, sedangkan sebaran data tidak normal pada perlakuan perendaman air perasan jeruk kesturi 5 hari $(p<0,05)$. Karena salah satu data tidak normal maka digunakan uji alternatif uji Repeated Anova, yaitu uji Friedman. Berikut adalah hasil analisis uji statistik Friedman dilengkapi dengan tambahan informasi nilai perbedaan rata-rata (mean), nilai signifikansi multivariate test, dan serta nilai signifikansi (Tabel 3).

Dari hasil analisis uji Friedman didapatkan bahwa nilai signifikansi adalah 0,000 yang berarti lebih kecil dari 0,05 $(p<0,05)$. Hal ini menunjukkan bahwa terdapat perbedaan perubahan warna yang bermakna antara perendaman 7 hari dalam larutan kopi, serta perendaman 60 menit dan 5 hari pada air perasan jeruk kesturi. Hasil Tabel 3 juga menunjukkan hasil uji beda lanjut nilai pengamatan warna. Hasil uji statistik terdapat perubahan warna yang signifikan antara perendaman 7 hari dalam larutan kopi, perendaman 60 menit dan 5 hari pada air perasan jeruk kesturi dengan nilai signifikansi 0,000 dan 0,005 yang berarti lebih kecil dari $0,05(\mathrm{p}<0,05)$. Pada hasil tersebut, diketahui bahwa semakin tinggi nilai $\Delta \mathrm{E}^{*}$ resin komposit, maka resin komposit semakin putih

Tabel 3. Tabel hasil uji Friedman

\begin{tabular}{ccccc}
\hline $\begin{array}{c}\text { Waktu } \\
(\mathrm{I})\end{array}$ & $\begin{array}{c}\text { Waktu } \\
(\mathrm{J})\end{array}$ & Sig. & Mean & $\begin{array}{c}\text { Sig. } \\
\text { (Multiv } \\
\text { a-riate } \\
\text { Test) }\end{array}$ \\
\hline Kopi & 60 &, 000 & 70,5810 & \\
& menit &, 005 & & \\
& 5 hari & & &, 000 \\
60 & Kopi &, 000 & 75,2730 & \\
menit & 5 hari &, 005 & & \\
5 hari & Kopi &, 005 & 83,3850 & \\
& 60 &, 005 & & \\
& menit & & & \\
\hline
\end{tabular}

\section{BAHASAN}

Penelitian ini diawali dengan perendaman 10 resin komposit dalam larutan kopi selama 7 hari agar terjadi diskolorisasi. Setelah itu, 10 sampel yang telah terdiskolorisasi direndam dalam air perasan jeruk kesturi selama 60 menit dan 5 hari. Waktu tersebut dipilih karena menurut penelitian yang dilakukan oleh Rochman tahun 2015 bahwa ada perubahan warna yang signifikan setelah direndam dalam jeruk selama 60 menit, dan penelitian Suprastiwi tahun 2005 mengatakan bahwa metode home bleaching memerlukan 112 jam atau 5 hari.

Pada hasil perendaman, dapat dilihat bahwa resin komposit yang telah direndam dalam larutan kopi mengalami perubahan warna yang bermakna pada perendaman air perasan jeruk kesturi selama 60 menit dan 5 hari. Perubahan warna resin komposit dilihat dari nilai pengamatan warna $\left(\Delta \mathrm{E}^{*}\right)$ yang semakin tinggi dengan pengukuran 
menggunakan CIEL*a*b analysis dengan perangkat lunak Adobe Photoshop dan kamera DSLR. Proses pengambilan foto pada tempat, posisi, pencahayaan, dan waktu yang sama pada setiap hari pengukurannya. Menurut Suratman metode ini efektif untuk melihat perubahan warna resin komposit pada saat penelitian. ${ }^{13}$

Hasil analisis data menggunakan uji Friedman menunjukkan bahwa terdapat pengaruh yang bermakna $(\mathrm{p}<0,05)$ antara sampel resin komposit yang direndam 7 hari dalam larutan kopi dan yang direndam dalam air perasan jeruk kesturi 60 menit dan 5 hari. Hal ini sejalan dengan penelitian sebelumnya yang dilakukan di Jember pada tahun 2015 oleh Rochman dan penelitian yang dilakukan oleh Ariana pada tahun 2015 tentang penggunaan air perasan jeruk sebagai bahan bleaching alternatif., 8,14

Resin komposit merupakan bahan tumpatan yang banyak dipakai karena keunggulan estetiknya yang menyerupai warna gigi walaupun selama pemakaiannya dapat mengalami perubahan warna. Diskolorisasi pada resin komposit merupakan masalah dalam upaya mempertahankan estetik bahan restorasi yang sewarna dengan gigi. ${ }^{15,16}$ Perubahan warna pada resin komposit karena faktor ekstrinsik dapat disebabkan salah satunya oleh zat warna dari minuman kopi apabila dikonsumsi secara berlebih. Berdasarkan penelitian yang dilakukan oleh Turkun pada tahun 2005, terdapat perubahan warna resin komposit yang telah direndam dalam larutan kopi selama 7 hari. ${ }^{17}$ Hal ini sejalan dengan penelitian yang peneliti lakukan yaitu terjadi perubahan warna setelah resin komposit direndam dalam larutan kopi selama 7 hari.

Pembersihan diskolorisasi atau bleaching eksternal merupakan solusi untuk mencerahkan gigi dan bahan tumpatan yang telah berubah warna karena faktor ekstrinsik dengan proses perbaikan secara kimiawi dengan tujuan mengembalikan fungsi estetiknya. ${ }^{18}$ Perubahan warna ekstrinsik lebih mudah direduksi dengan bahan bleaching dibandingkan perubahan warna intrinsik.
Bahan bleaching mengandung bahan kimiawi yang menimbulkan efek samping antara lain iritasi gingiva dan resorpsi eksterna di bagian servikal. ${ }^{6}$

Bahan bleaching juga dapat menimbulkan efek negatif pada resin komposit, seperti merubah kekerasan permukaan restorasi, menambah kekasaran serta keretakan dan marginal microleakage pada restorasi. Kekasaran permukaan restorasi resin komposit merupakan suatu hal yang penting bagi para peneliti dan praktisi karena kekasaran permukaan berhubungan dengan retensi plak yang dapat menyebabkan inflamasi gingiva dan awal karies. Kolonisasi bakteri berawal dari keadaan permukaan yang tertimbun plak. Selain itu, warna dari resin komposit dapat menjadi lebih gelap karena adanya permukaan yang kasar dan tidak memantulkan cahaya sehingga mengurangi estetik. Akibat efek samping dari bahan bleaching maka banyak penelitian dilakukan untuk mencari bahan alternatif bleaching yang berfungsi untuk memutihkan dan mencerahkan gigi yang telah mengalami diskolorisasi. ${ }^{19}$

Bahan alami yang dapat menjadi bahan alami alternatif bleaching adalah jeruk kesturi karena mengandung asam sitrat yang diketahui dapat menjadi oksidator kuat sehingga dapat memberi efek pemutihan. ${ }^{10}$ Jeruk kesturi banyak dijumpai di Sulawesi Utara dan harganya terjangkau. Hasil penelitian menunjukkan bahwa resin komposit yang telah terdiskolorisasi mengalami perubahan warna menjadi lebih putih setelah direndam dalam air perasan jeruk kesturi seperti yang ada di Tabel 1. Pengaruh perendaman dengan air perasan jeruk kesturi terhadap perubahan warna resin komposit dapat disebabkan oleh adanya asam sitrat yang terkandung dalam jeruk kesturi. Berdasarkan penelitian Rochman, asam sitrat yang terkandung dalam jeruk memiliki potensi yang sama dengan bahan bleaching hidrogen peroksida untuk mencerahkan warna resin komposit karena memiliki banyak unsur $\mathrm{OH}$, sehingga mampu merusak molekul-molekul zat 
warna dan warna menjadi lebih terang. ${ }^{8}$

Hasil penelitian ini menunjukkan bahwa jeruk kesturi dapat meningkatkan tingkat kecerahan resin komposit dengan baik, namun dapat juga menimbulkan microleakage pada resin komposit apabila terpapar dalam jangka waktu yang panjang. Jeruk kesturi memiliki pH 2 setelah diukur dengan $\mathrm{pH}$ indikator. Ini menunjukkan bahwa jeruk kesturi memiliki kandungan asam yang cukup tinggi sehingga dapat menimbulkan erosi pada gigi. Erosi diketahui dapat menyebabkan demineralisaasi jaringan keras gigi dan mempengaruhi bahan restorasi gigi. ${ }^{1}$

Penelitian ini memiliki keterbatasan yaitu tidak dapat mengetahui tingkat konsentrasi jeruk kestui yang aman digunakan untuk mencerahkan warna resin komposit tanpa terjadinya proses microleakage pada restorasi. Penelitian sebelumnya menyarankan untuk membilas atau menyikat gigi setelah mengonsumsi buah jeruk kesturi untuk menghindari efek samping yang dapat timbul. Selain itu, dapat juga mengontrol penggunaan jeruk kesturi dengan mengurangi volume pemakaiannya agar tidak terlalu berlebihan. $^{20}$

Keterbatasan penelitian ini yaitu tidak terdapat kelompok kontrol untuk menjadi pembanding. Pada penelitian ini, kelompok sampel resin komposit yang terdiskolorisasi diberi perlakuan perendaman air perasan jeruk kesturi dengan dua waktu yang berbeda dan hasilnya diteliti, namun belum diketahui apakah masih terdapat variabel luar yang ikut memengaruhi perubahan warna resin komposit karena tidak ada kelompok pembanding atau kelompok kontrol.

\section{SIMPULAN}

Dari hasil penelitian dapat disimpulkan bahwa terdapat pengaruh dari jeruk kesturi (Citrus microcarpa Bunge.) terhadap perubahan warna resin komposit yang direndam dalam larutan kopi.

\section{SARAN}

Perlu dilakukan penelitian lebih lanjut untuk mengetahui tingkat konsentrasi dan keasaman dari jeruk kesturi yang efektif dan aman untuk digunakan.

Perlu adanya penelitian lebih lanjut untuk mengembangkan penelitian ini dengan menggunakan jenis resin komposit yang lain untuk dibandingkan dengan resin komposit nanohybrid dengan jumlah sampel yang lebih banyak dan memakai kontrol sehingga hasil yang didapatkan lebih akurat.

\section{DAFTAR PUSTAKA}

1. Tin-Oo MM, Saddki N, Hassan N. Factors influencing patient satisfaction of dental appearance and treatments they desire to improve aesthetics. BMC Oral Health. 2011;11(6):1-8.

2. Ilie N, Hickel R. Investigations on mechanical behaviour of dental composites. Clinical Oral Investigations. 2009;13(4):427-38.

3. Hattab FN, Qudeimat MA, Al-rimawi HS. Dental discoloration: an overview. Journal of Esthetic Dentistry. 2000;11(6):291.

4. AEKI (Asosiasi Ekspoktir dan Industri Kopi Indonesia). Konsumsi Kopi Indonesia. [cited 18 Maret 2016] Available from: URL : http://www.aekiaice.org/page/konsumsi-kopidomestik/id

5. Walton RE, Torabinejad M. Prinsip dan Praktik Ilmu Endodonsia (2nd ed). Juwono L, editor. Jakarta: EGC, 2008; p. 453-63.

6. Mitchell L, Mitchell DA, McCaul. Kedokteran Gigi Klinik (5th ed). Alih bahasa: Purwanto et al; Editor: Nurul D, Juwono L. Jakarta: EGC, 2014; p. 284-5.

7. Suwakbur S. Perbandingan efektivitas buah stroberi (Fragaria $x$ annanassea) dengan buah tomat (Lucopersicon esculentum mill) sebagai bahan alami pemutih gigi (secara in vitro) [Skripsi]. Makassar: Universitas Hasanuddin; 2015.

8. Rochman N. Efek air perasan jeruk nipis (Citrus aurantifolia) terhadap email gigi yang mengalami diskolorasi [Skripsi]. Jember: Universitas Jember; 2015. 
9. Puspasari N, Effendi C, Nugraeni Y. Effect of apple juice on whitening teeth after immersion in coffee solution in vitro [Skripsi]. Malang: Universitas Brawijaya; 2012.

10. Cheong MW. Chemical Components and Aromatic Profiles of Citrus and Coffee in Asia. Thesis. Department of Chemistry: National University of Singapore. 2013. p.238

11. Batugal PA, Kanniah J, Lee SY, Oliver JT, editors. Medicinal Plants Research in Asia, Volume 1: The Framework and Project Workplans. International Plant Genetic Resources Institute: Regional Office for Asia, the Pacific and Oceania (IPGRIAPO), Serdang, Selangor DE, Malaysia, 2004; p. 161.

12. Perez MM, Saleh A, Yebra A, Pulgar R. Study of the varation between CIELAB $\triangle E^{*}$ and CIEDE2000 color differences of resin composites. Dental Materials Journal. 2006;26(1):21-8.

13. Suratman. Perbedaan diskolorisasi restorasi resin komposit pada perendaman larutan teh hijau dan teh hitam [Skripsi]. Makassar: Universitas Hasanuddin; 2014.

14. Ariana TR, Wibisono G, Praptiningsih RS. Pengaruh perasan buah lemon terhadap peningkatan warna gigi. Med J. 2005;2(1): 74-8.

15. Ferracane JL. Resin composite-state of the art. Dental Materials. 2011;27:2938.

16. Ibrahim MAM, Bakar WZ, Husein A. A comparison of staining resistant of two composite resins. Arch Orofacial Sci. 2009;4(1):13-6.

17. Turkun LS, Turkun M. Effect of bleaching and repolishing procedures on coffee and tea stain removal from three anterior composite veneering materials. J Esthet Restor Dent. 2004; 16(5):290-301.

18. Ren YF, Amin A, Malmstrong H. Effect of tooth whitening and orange juice on surface properties of dental enamel. Journal of Dentistry 2009; 30: 1-2.

19. Dhurohmah, Rochman M, Chumaeroh S. Pengaruh waktu polishing dan asam sitrat terhadap microleakage pada tumpatan resin komposit nanofiller Aktivasi Light Emiting Diode - In Vitro. ODONTO Dental Journal 2014; 1(1): 13-5

20. Chrismayani NKP. Manfaat pasta lemon sebagai bahan alami pemutih gigi [Skripsi]. Denpasar: Universitas Mahasaraswati; 2014. 